\title{
Über Diamidopyren.
}

Von Rudolph Jahoda.

(Aus dem Universitäts-Laboratorium des Prof. v. Barth.)

(Vorgelegt in der Sitzung am 21. Juli 1887.)

Gelegentlich der Nitrirung des Pyrens wurde, wie schon oben erwähnt, eine nicht unbeträchtliche Menge von Dinitropyren erhalten; dasselbe wurde nach den Angaben von Goldschmiedt ${ }^{1}$ gereinigt.

Eine Stickstoffbestimmung nach Kjeldabls Methode erforderte fur $0.4357 \mathrm{Grm}$. Substanz $30 \cdot 8$ CC. Schwefelsäure vom Titer $1 \mathrm{CC} .=0.004862 \mathrm{Grm} . \mathrm{H}_{2} \mathrm{SO}_{4}$

in 100 Theilen :

$$
\underbrace{\text { Gefunden }}_{N=9 \cdot 82} \quad \frac{\text { Berechnet }}{9 \cdot 59}
$$

Es wurde bierauf mit Zinn und Salzsäure reducirt, bis die Farbe der Verbindung nur noch schwach gelblich erscheint.

Das Diamidopyren bildet wie auch die Monamidoverbindung bei dieser Operation kein Zinndoppelsalz. Das Filtrat von dem Chlorhydrat wurde mit Schwefelwasserstoff behandelt und eingeengt; es schieden sich aus dem licht bernsteingelben Filtrat gelbe, feine Nadeln aus, die sich als das Chlorhydrat des Diamidopyren erwiesen.

0·1554 Grm. Substanz geben an Kohlensäure 0.4150 Grm. und an Wasser $0.0750 \mathrm{Grm}$. daraus

in 100 Theilen:

\begin{tabular}{|c|c|}
\hline Gefunden & Berechnet \\
\hline $\mathrm{C}=72 \cdot 82$ & $71 \cdot 50$ \\
\hline$H=5 \cdot 36$ & $5 \cdot 21$ \\
\hline
\end{tabular}

1 Monatshefte f. Chemie, Juli 1881. 
Da somit die Löslichkeit des Chlorhydrates in Wasser erwiesen war, wurde die ganze Menge umzukrystallisiren versucht; es fand aber dabei sofort Dunkelfärbung und Abscheidung einer beträchtlichen Schmiere statt. An eine Reindarstellung auf diese Weise war nicht zn denken. Als bester Weg zur Gewinnung der Base eignet sich folgender:

Die Lösung wird mit Äther überschichtet und mit kohlensaurem Natron zerlegt. Nach dem Umschütteln geht die Base leicht, und bei genügender Menge Äther, vollständig in denselben iiber. Dieser wird abgegossen, reines Wasser zugesetzt und mit einigen Tropfen Schwefelsüure versetzt. Nach dem Umschiitteln wird die wässerige Schichte tief dunkelroth gefärbt und das Sulfat bleibt zum grössten Theile (noch in sehr unreinem Zustande), in derselben suspendirt. Wird nun neuerdings kohlensaures Natron zugesetzt, wobei ein grosser Überschuss vermieden werden soll, so geht die Base wieder in Äther über, und an der Berihrungsfläche bleibt ziemlich viel einer schwarzen Schmiere zurick. Diese wird entfernt, neues Wasser und neue Schwefelsäure zugesetzt und wie oben beschrieben verfahren.

Diese Operation wird so lange fortgesetzt, bis sich keine Schmiere mehr ablagert; es reichte dazu dieselbe Quantität Äther ans, da ja der Verlust nur ein sehr geringer ist.

Anch bietet diese Methode eine bedeutende Ersparniss an Zeit, da das lästige Abdestilliren des Äthers entfällt; es lässt sich somit die Operation sehr oft innerhalb einer Stunde ausführen.

Das schw e felsa ure Diamid opyren fällt aus Äther ganz weiss heraus, wird aber beim Trocknen grau. Der Schmelzpunkt konnte wegen der leichten Zersetzbarkeit aller dieser Diamidoverbindungen nicht bestimmt werden.

0.1401 Grm. Substanz im Vacuum getrocknet gaben $0.2993 \mathrm{Grm}$. Kohlensäure und $0.0608 \mathrm{Grm}$. Wasser in 100 Theilen:

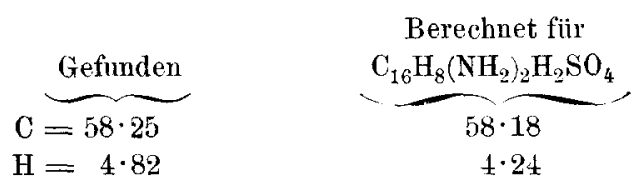

Das Sulfat ist in Wasser wie auch in Alkohol ganz unlöslich. 
Das Diamidopyren selbst konnte wobl aus der Lösung des Chlorhydrates abgeschieden werden, war im Momente des Ausfallens sehr schön gelb gefärbt, um aber alsbald sich zu verschmieren, wozu auch alle Salze grosse Neigung haben, wofern sie nicht in ganz reinen Zustande sich befinden.

In verdünnter alkoholischer oder ätherischer Lösung zeigt das Diamidopyren eine prachtvolle, blaue Fluorescenz in fast noch höherem Grade als das Monoproduct. 